\title{
Erratum to: Toxicity of two types of silver nanoparticles to aquatic crustaceans Daphnia magna and Thamnocephalus platyurus
}

\author{
Irina Blinova • Jukka Niskanen • Paula Kajankari • \\ Liina Kanarbik • Aleksandr Käkinen • Heikki Tenhu • \\ Olli-Pekka Penttinen • Anne Kahru
}

Published online: 27 April 2013

(C) Springer-Verlag Berlin Heidelberg 2013

\section{Erratum to: Environ Sci Pollut Res}

\section{DOI 10.1007/s11356-012-1290-5}

Unfortunately, there was an error on the title of Table 4 in the original publication of this article.

Instead of "Acute toxicity, E(L) C50, of the Ag compounds to crustaceans in six different test media, in micrograms $\mathrm{Ag} / \mathrm{L}$ " it should have been "Table 4 Acute toxicity, E(L) $\mathrm{C} 50$, of the Ag compounds to crustaceans in six different test media, in micrograms $/ \mathrm{L}(\mu \mathrm{g} \mathrm{Ag} / \mathrm{L})$ "

The online version of the original article can be found at http://dx.doi.org/ 10.1007/s11356-012-1290-5.

I. Blinova $(\varangle) \cdot$ L. Kanarbik $\cdot$ A. Käkinen $\cdot$ A. Kahru

Laboratory of Molecular Genetics, National Institute of Chemical

Physics and Biophysics, Akadeemia tee 23, Tallinn 12618, Estonia

e-mail: irina.blinova@kbfi.ee

J. Niskanen $\cdot$ H. Tenhu

Laboratory of Polymer Chemistry, Department of Chemistry,

University of Helsinki, P.O. Box 55, 00014 Helsinki, Finland

P. Kajankari $\cdot$ O.-P. Penttinen

Department of Environmental Sciences, University of Helsinki,

Niemenkatu 73, 15140 Lahti, Finland

L. Kanarbik $\cdot$ A. Käkinen

Department of Chemical and Materials Technology, Tallinn

University of Technology, Ehitajate tee 5, Tallinn 19086, Estonia 